\title{
Discussion on Modern Art Application in Garden Environmental Art Design
}

\author{
Xiangkai Wu \\ Nanyang Institute of Technology, Nanyang, Henan Province, China
}

Keywords: modern art, landscape architecture, environmental art, design, application

\begin{abstract}
Traditional art is the essence of China's modern culture. Its application in design is not uncommon. In the contemporary environment of art design, the combination of modern culture and traditional materials with modern design has achieved good results and received more and more people's attention and love. How to combine tradition and modernity in environmental art design and how to promote the sustainable development of modern culture in the design are important issues that need to be considered in environmental art design. Based on this, this paper also elaborates the modern culture in environmental art design and reveals its form and future development trend. It is hoped to provide some reference for the development of environmental art design.
\end{abstract}

\section{Introduction}

Cultural traditions are the quintessence of our history and culture and play a decisive role in the long history of our country. They have also nourished the people of Huaxia from generation to generation, so that people can be baptized in the long river of culture. With the development of society, people's need for life has not only satisfied with the adequate food and clothing, but also started to pursue more spiritual needs and enjoyment [1]. Environmental art design came into being. The existence and development of environmental art design provide people with a more comfortable living environment and meet the needs of the spiritual world in the living environment. How to integrate modern environmental art design with modern culture and how to combine the traditional elements in modern environmental art design perfectly with the modern is an important part of how to treat and think seriously.

\section{Modern art in environmental art design}

\subsection{Nationality in environmental art design}

Since the beginning of the last century, the pursuit of the "berthed" culture has reached an all-time high. The prevalence of the Southeast Asian style and the prevalence of retro-style European and American art have gradually hurled our modern art to the point of being almost forgotten [1]. However, with the rational return of people, after the period of wandering and blind follow-up, the perspective of environmental art design gradually returns to the modern art elements of our country. The most important thing in modern art in environmental art design is to reflect the national characteristics of our country. Environmental art design must base itself on the modern art of its own people, absorb eclectic culture eclectically, make up for the shortcomings of its own national culture, develop the characteristics and characteristics of its own nation, design based on the basic needs and basic lifestyles of our people, in order to make the environmental art design vivid, with a national foundation. Otherwise, environmental art design will become a waterless wood, rootless source.

\subsection{Cultural design in environmental art design}

Environmental art design also pay attention to the cultural art of traditional arts. To add the traditional elements to the modernization of environmental art and design is not to simply list the traditional elements but to integrate them according to the cultural connotation of the traditional elements and make overall planning [2]. The world has been tilted to the east. More and more foreigners are paying attention to the oriental world and the oriental world's culture. Environmental art design should reflect the cultural characteristics of our nation and reflect the history and culture of 
our country. Different elements reflect the same national culture. In environmental art design, more should reflect the advanced, civilized and scientific culture of our country and carry forward our country's modern art.

\subsection{Regional design in environmental art}

The most important aspect of environmental art design is the localization after rational regression. In environmental art design, we should pay more attention to what is derived from the traditional internal structure, pay attention to our own uniqueness, pay attention to integrating cultural contents in developing areas or regions with special features in our country, and pursue cultural regionalism, local characteristics and national culture. Integrate the cultural elements of the region into the design of environmental art and reflect the cultural geography in environmental art design [2]. This is a cultural rebound, but also a cultural reflection, but also a cultural application. It is of great importance to put forward the cultural regionalism in environmental art design.

\section{Application of modern art in garden environmental art design}

When integrating the elements of modern art into the design of landscape environment, we should pay attention to the manifestation of the elements of modern art, highlight the cultural connotation through the use of microscopic features, and strive to achieve the special effect of "a drop of water meets the sun." Through the prediction of the future development trend of the modern art elements in the garden environment art design, the application of modern art in the design of the garden environment is promoted.

The elements of modern art in the garden environment art design in a variety of forms, designers want to use their own unique ideas and ideas to be flexibly applied to make it show different characteristics and characteristics. The elements of modern art are the design of landscape environment art mainly in the following aspects.

\subsection{Embodiment of modern art in design of space garden environment}

Spatial layout design is the primary content of the design of landscape environment, which mainly involves the site selection, site analysis, spatial distribution and so on. The level of landscape environment, the level of integration of the degree of flexibility, depends on the degree of flexibility in the use of space, shown as Fig. 1.

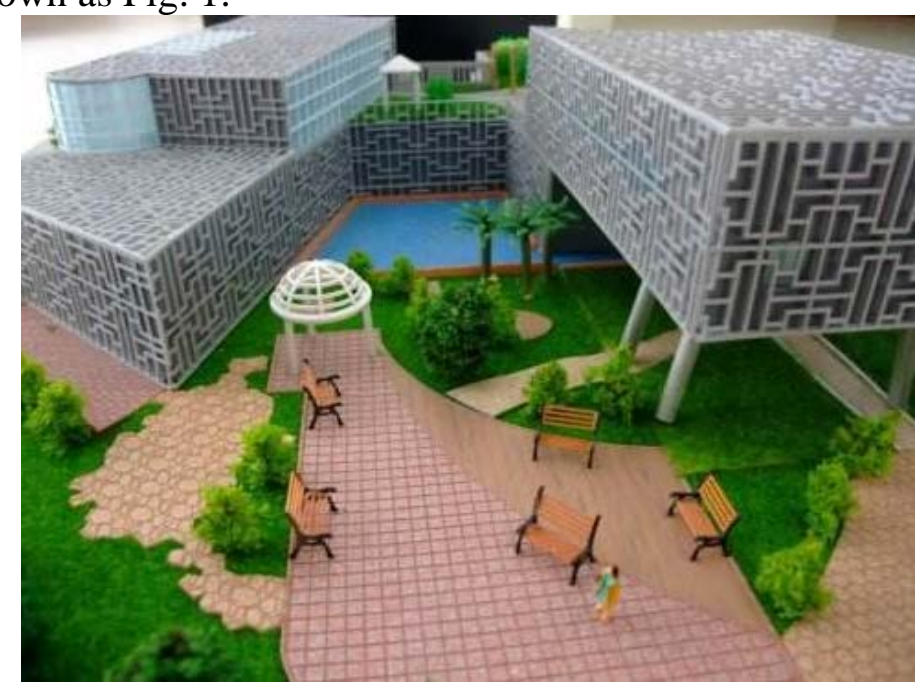

Fig. 1 Embodiment of modern art in design of space garden environment.

In addition, when building the spatial distribution of cities, it is also necessary to carefully consider the space proportion, the sense of spatial rhythm, the sense of spatial rhythm and the sense of contrast at the spatial level in combination with the related principles of art form beauty. For example, Spain's Plaza North Station, built in 1991 in Barcelona, is a plaza of art and culture that uses the plasticity of its spatial layout. When carrying out the layout design of the space, the designer has simplified the 
contradiction between the urban network system and the base on the basis of meeting the function of using the park, and successfully designed a structured space art system [3].

\subsection{The design of spatial flow in the design of landscape environment}

In the design of modern garden environment space, the application of the method of spatial flow enables people to experience the time stagnation during the tour. Through the perfect interspersing between the historical scenery and the modern scenery, it shows the different landscape space order, shown as Fig.2. The typical representative of the German Pavilion in Barcelona, Spain, in its interior, has played the role of structural support for the pillars, while the walls are freely arranged, combined with the combination of landscape language structure, creating a vivid image of the outdoor landscape space.

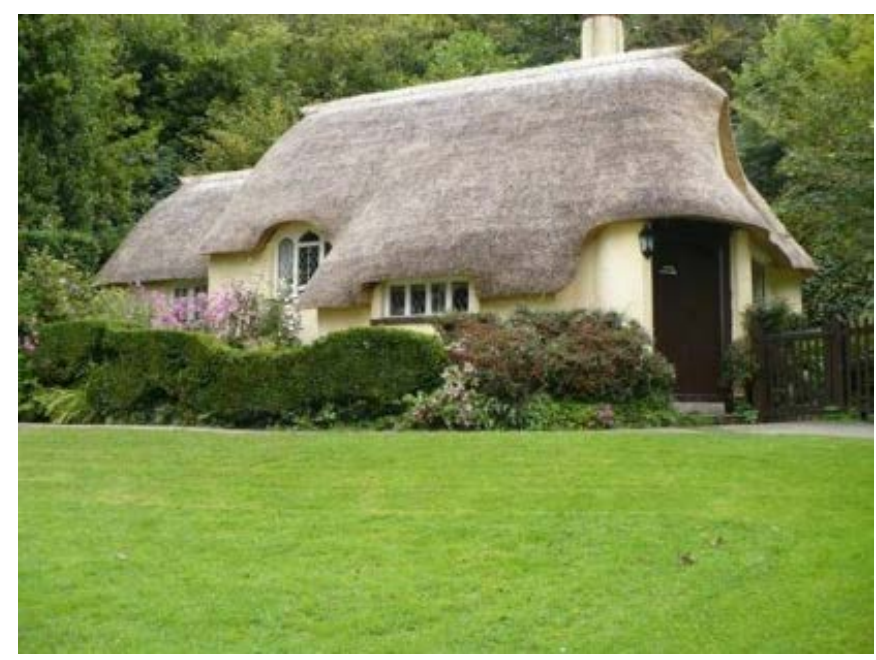

Fig. 2 The design of spatial flow in the design of landscape environment

\subsection{Embodiment of grid design in the design of garden environment}

In the design of garden environment space, the grid design method is mainly used because the grid boundary nodes can expand freely and infinitely, and can form a strong horizontal perspective effect in a single space, regardless of the direction of the space, the same direction, shown as Fig.3. When designing the garden, separate the space with simple building walls, and then use the green walls such as arbors, flowers and other green walls to strictly separate the grid plane. Finally, planted the vegetation with simple rules such as squares and straight lines achieve the purpose of space combination [4]. The typical grid design method is the South Art Association of Chicago, USA, Philadelphia Independence Avenue and so on. Designers are using the characteristics of grid space for multi-order superposition, plus vegetation modification, making the space "transparency" increases.

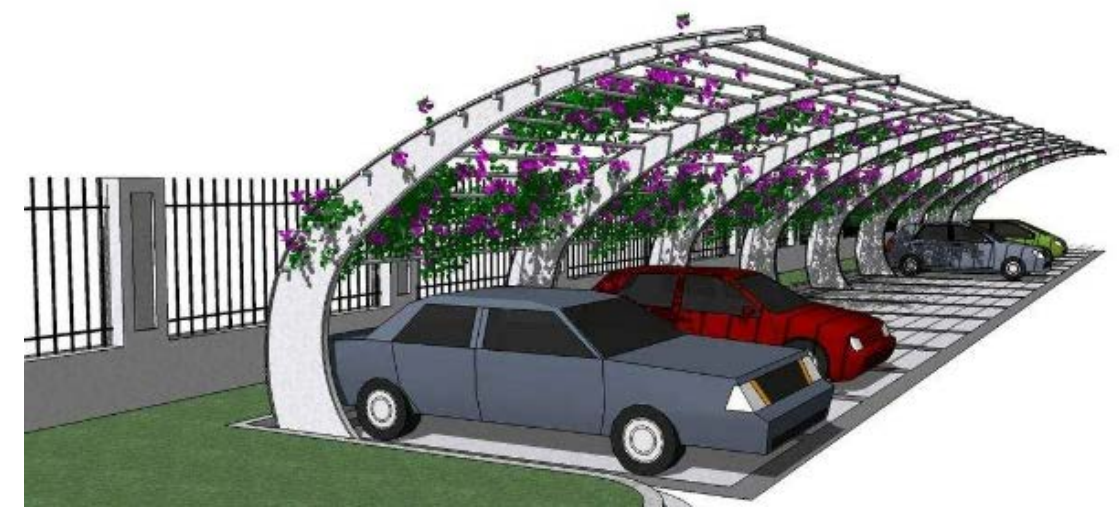

Fig. 3 Embodiment of grid design in the design of garden environment

\subsection{Modern sculpture art in landscape design}

Throughout the current design of the garden environment, the basic inseparable from the sculpture 
of sculpture, it can make the city more rhythmic sense of hierarchy and vitality, shown as Fig.4. In recent years, more and more sculptural materials can be used, not only from the interior to the outdoors, but also its artistic style and tendency to diversify so that the viewer can profoundly appreciate its unique artistic charm [3]. In the garden design, more and more vegetation sculptures are presented in front of the general public, becoming the focus of the unusual shine in the city landscape.

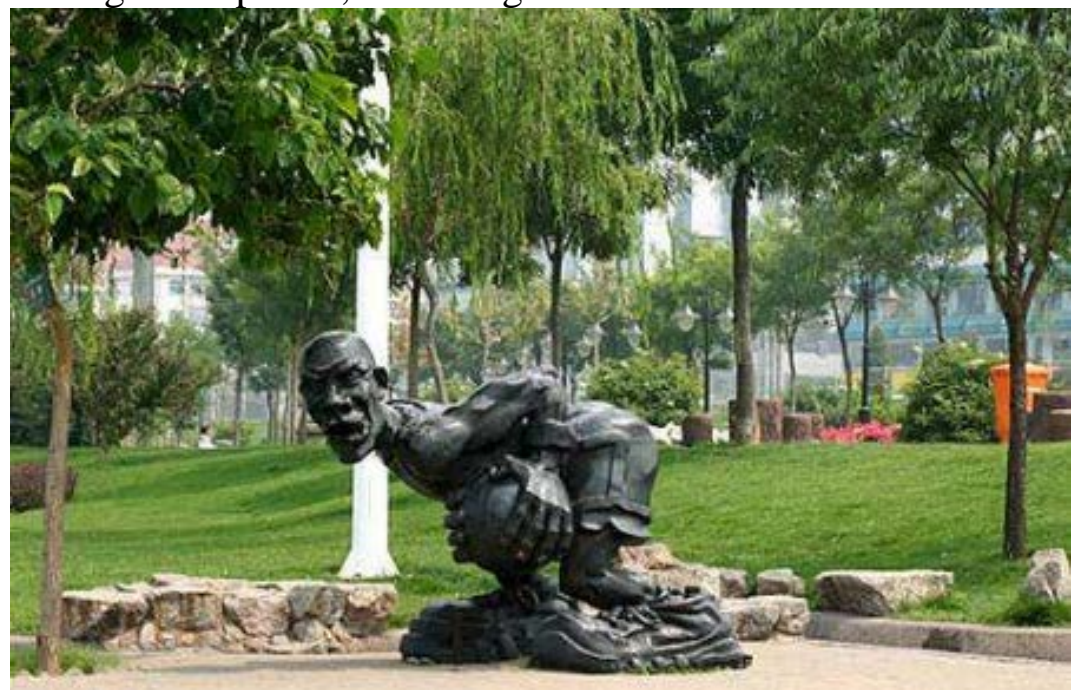

Fig.4 Modern sculpture art in landscape design

\subsection{Reflecting on the art of landscape painting in landscape design}

Soft lines and colors are the most common basic elements in the design of garden environment. From a certain level, modern garden art is also the embodiment of painting art [5]. Well-known landscape architect Bream in the design of the garden (shown as Fig.5), they are good at abstract art painting which is applied to the characteristics of different vegetation based on the color change, after the contrast between the depth of color, composed of free and changeable color form, to achieve the harmony of design Unite.

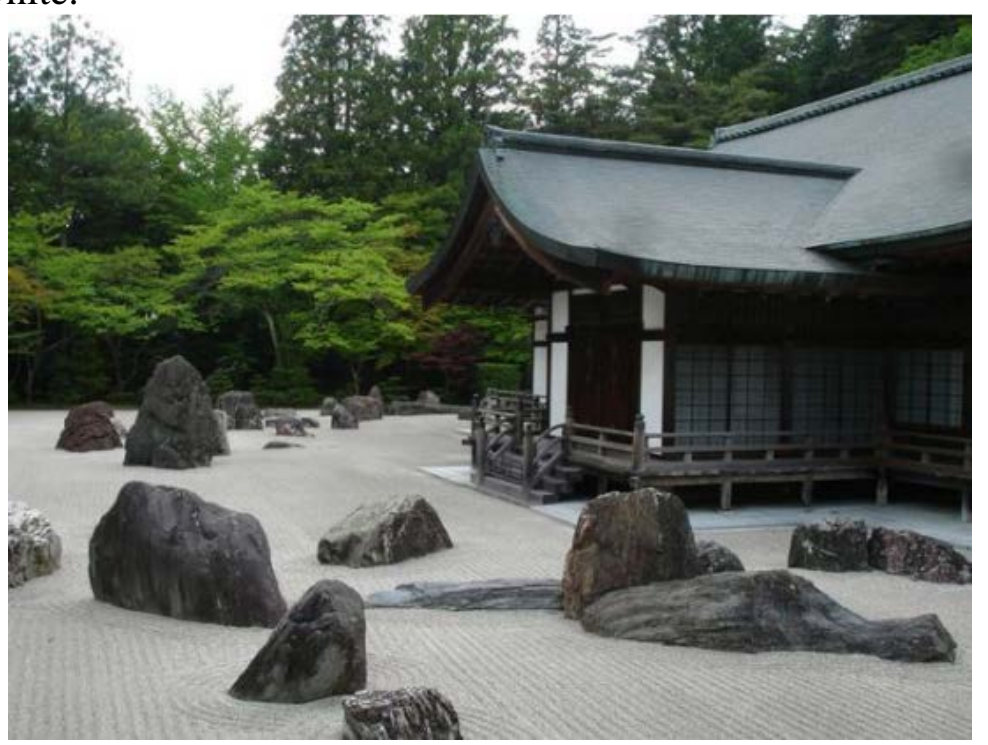

Fig. 5 Reflecting on the art of landscape painting in landscape design

\subsection{Vegetation and other environmental design in the garden reflects}

Bamboo, lawn and so on play a finishing touch in landscape design. They are located in various places in the city such as plazas, green spaces and parks. They reflect the vitality of the city through eye-catching colors and special morphological changes. Vegetation in the garden design is an essential element. In the design of the local climate and environment characteristics, soil characteristics and hydrological characteristics to choose the right type of vegetation. Vegetation 
color design and sketches the same, can increase the garden design features. In addition, from the point of view of modern art ecology, the mix and match of different colors, levels and vegetation can make people feel different coordination while visiting the garden [5].

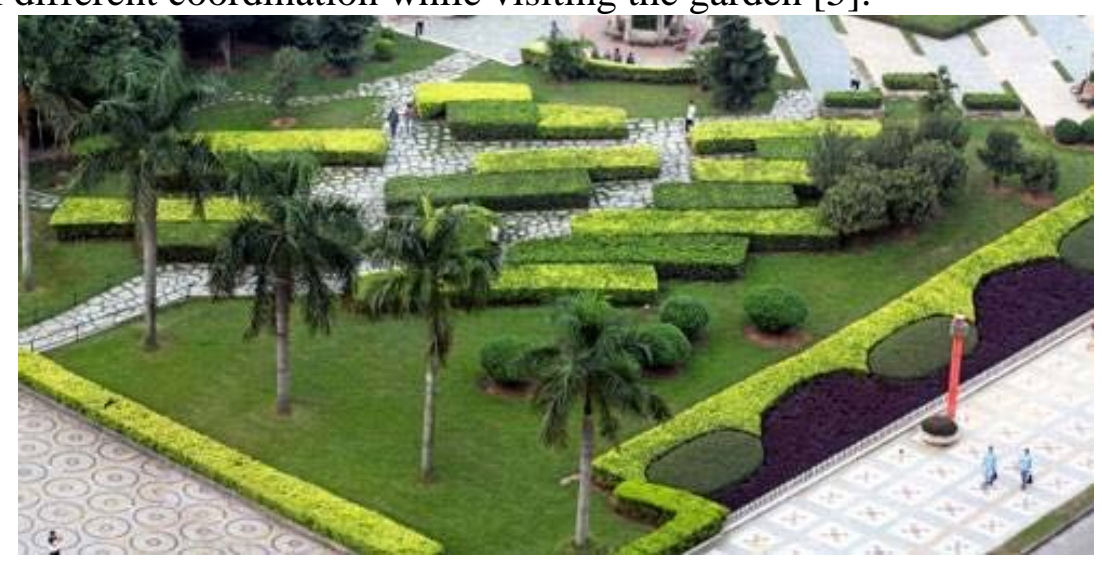

Fig. 6 Vegetation and other environmental design in the garden reflects

\section{Conclusions}

The rapid socio-economic development has made people pay more attention to the spiritual life, environmental art design to join the modern art can well meet people's needs. However, the combination of modern art and landscape design is not accomplished in one go. If you want to combine the two perfectly, you need to keep practicing and exploring, and try to make innovations in practice so as to seize the traditions of environmental art design Key elements of the elements, through continuous improvement to meet people's growing cultural needs.

\section{References}

[1] Z.T. Wen, Statistical analysis of the status quo of Chinese garden industry, Modern decoration, 2010, vol. 7, pp. 6-9.

[2] Y.T. Liu, Concept of modern art in landscape environment design, Heilongjiang Science, 2013, vol.11, pp.240-242.

[3] D.T. Ding, The return of Chinese modern art in landscape design of landscape architecture, Art Technology, 2014, vol.12, pp. 150-153.

[4] Y.Q. Fan, Artistic conception of modern art in the design of garden environment, Journal of Jilin Institute of Education 2015, vol.2, pp.146-149.

[5] J.T. Hou and W.J. Shang, Concept of modern art in garden environment art design, Modern Decoration, 2014, vol.6, pp. 131-134. 